\title{
POLÍTICAS DE CERTIFICACÃO DE SABERES D0 TRABALHO NO BRASIL: A CONSTRUÇÃO DA REDE CERTIFIC
}

\author{
WORK-BASED KNOWLEDGE CERTIFICATION POLICIES IN BRAZIL: THE \\ IMPLEMENTATION OF THE REDE CERTIFIC \\ POLÍTICAS DE CERTIFICACIÓN DE LOS SABERES DEL TRABAJO EN BRASIL: \\ CONSTRUCCIÓN DE LA RED CERTIFIC
}

RESUMO: Este artigo analisa os marcos legais que dispõem sobre a certificação profissional com base no reconhecimento de saberes construídos na experiência de trabalho, no lastro de políticas públicas que visam a assegurar direitos do trabalho e da educação. Partindo da promulgação da Lei ${ }^{0}$ 9.394/96, instrumento que amplia o conceito de educação e também dos processos educativos, apresentam-se os dispositivos legais que emergem para regulamentar os dispostos sobre a educação profissional e reconhecimento de saberes. Posteriormente, serão apresentadas as políticas públicas voltadas para certificação profissional, as quais surgem a partir do reconhecimento de outros locais, que não a escola, como ambientes de construção de conhecimento. Finalmente, discorrere-se sobre a implementação da Rede Nacional de Certificação Profissional - Rede CERTIFIC, elaborada em uma ação articulada entre Ministérios da Educação e do Trabalho.

Palavras-chave: Certificação Profissional. Reconhecimento de Saberes. Políticas públicas. Rede Certific.

ABSTRACT: This paper analyses the legal frameworks that treat about professional certification based on the recognition of knowledge built on work experience, on the back of public policies aimed to ensuring labor and educational rights. Starting from the promulgation of the Law 9.394/96, which extends the concept of education and also the concept of educational processes, we will present the legal devices that emerge to regulate the willing about professional education and recognition of knowledge. Later, will be presented public policies geared towards professional certification, which arise from the recognition of other places, not the school, as knowledge building environments. Finally, we will treat the implementation of the Rede Nacional de Certificação Profissional - Rede CERTIFIC, performed by a joint action between the Ministries of Education and Labor.

Keywords: Professional Certification. Knowledge Recognition. Public Policies. Rede Certific.

RESUMEN: Este artículo analiza los marcos legales que disponen sobre la certificación profesional basada en el reconocimiento del conocimiento construidos en la experiencia de laboral en el lastre de las políticas públicas destinadas a garantizar los derechos laborales y de la educación. A partir de la promulgación de la Ley 9.394/96, un instrumento que amplía el concepto de la educación y también de los procesos educativos, se presentan las disposiciones legales que surgen para regular las disposiciones sobre la formación profesional y el reconocimiento de los saberes profesionales. Más tarde, se presentan las políticas públicas de la certificación profesional, que surgen del reconocimiento de otros sitios, y no a la escuela, como sitios de creación de conocimiento. Por último, discutiremos sobre la implementación de la Red Nacional de Certificación Profesional - CERTIFIC, desarrollada en una acción coordinada entre los Ministerios de Educación y de lo Trabajo.

Palabras clave: Certificación Profesional. Reconocimiento de los Saberes. Políticas Públicas. Certific. 
* Doutoranda em Educação pela Faculdade de Educação da Universidade Federal de Minas Gerais (FaE/UFMG). Mestra em Educação pela FaE/UFMG. Graduada em pedagogia.

** Professora Associada da Faculdade de Educação da UFMG. Doutora em Filosofia (Epistemologia e História da Filosofia) pela Aix-Marseille Université.
1 Mais informações em: A certificação profissional e de pessoas: relato de algumas experiências brasileiras (STEFFEN, 2010).

\section{INTRODUÇÃO}

Verificamos atualmente o crescimento de discussões que enfatizam a necessidade de criação de estratégias que valorizem as aprendizagens realizadas pelos sujeitos ao longo de sua vida. Nesse entendimento, há uma ampliação do tempo e do espaço educativo para além das formas institucionalizadas de educação e reconhece-se que a educação se estende a diferentes contextos sociais, tais como o trabalho, as atividades comunitárias e a vida familiar, que, por sua vez, constituem-se como lócus de produção de saberes. Assim sendo, a aprendizagem não está mais delimitada ao tempo de escolarização formal, considerando-se e exigindo-se que ela aconteça continuamente no decorrer da vida do indivíduo.

Emergem, nesse contexto, demandas por iniciativas que busquem desenvolver metodologias que viabilizem o reconhecimento social de aprendizagens construídas na/pela experiência (ALCOFORADO, 2008; MORAES; NETO, 2005; LIMA, 2011, 2015). Nesse sentido, constata-se, no decorrer das últimas três décadas, que diferentes países vêm elaborando sistemas voltados para a avaliação e o reconhecimento de saberes da experiência (COLARDYN; BJORNAVOLD, 2004).

Diante desse quadro, o governo brasileiro vem desenvolvendo e implementado políticas públicas que procuram avaliar e certificar os saberes dos trabalhadores, independentemente de sua inserção em rotas de formação profissional institucionalizadas. Essas iniciativas podem ser rastreadas ao começo da década de 1970, através da implantação do projeto formulado pelo Centro Interamericano de Investigação e Documentação sobre Formação Profissional (CINTERFOR-OIT). Desde essa época, surgiram no Brasil vários programas voltados para a certificação profissional de saberes e competências. Estes foram implementados por diversos agentes sociais (ONGs, sindicatos, empresas etc.), e os principais organismos de certificação estão vinculados ao Instituto Nacional de Metrologia, Normalização e Qualidade Industrial - INMETRO. ${ }^{1}$

Apesar de reconhecer-se a importância desses organismos no desenvolvimento de programas de certificação profissional, essa comunicação almeja realizar um mergulho histórico nas iniciativas de certificação desenvolvidas pelo Governo Federal. O objetivo é apresentar marcos legais de dispositivos de certificação profissional com base no reconhecimento de saberes construídos na experiência de trabalho, no lastro de políticas públicas que visem a assegurar direitos do trabalho e da educação.

Para o desenvolvimento desta pesquisa, realizamos uma revisão documental abordando os textos legais brasileiros que versam sobre o reconhecimento de saberes para fins de certificação profissional. No curso desse trabalho, apresentaremos brevemente as principais iniciativas governamentais voltadas para a criação de um sistema 
nacional de certificação profissional. Por fim, discorreremos sobre a implementação da Rede Nacional de Certificação Profissional (Rede CERTIFIC), a qual se constitui como a última tentativa governamental para o desenvolvimento de um sistema nacional de reconhecimento de saberes e certificação profissional.

\section{DISPOSIÇÕES LEGISLATIVAS SOBRE CERTIFICAÇÃO PROFISSIONAL}

Os dispositivos legais brasileiros que versam sobre a educação surgidos a partir da segunda metade da década de 1990 trazem em seu texto um conceito ampliado sobre o que é a educação e como ela se dá. A promulgação da Lei $\mathrm{n}^{0}$ 9.394/96, que estabelece as diretrizes e bases da educação nacional (LDBEN), é um marco deste movimento, uma vez que o seu artigo primeiro define que "A educação abrange os processos formativos que se desenvolvem na vida familiar, na convivência humana, no trabalho, nas instituições de ensino e pesquisa, nos movimentos sociais e organizações da sociedade civil e nas manifestações culturais" (BRASIL, 1996). Legitimam-se, assim, diferentes espaços sociais como lócus de formulação e aquisição de conhecimentos, altera-se o papel hegemônico do conhecimento escolar e coloca-se o problema do reconhecimento dos saberes construídos em ambientes "informais".

Complementando o disposto no artigo primeiro, no âmbito da Educação Profissional e Tecnológica, a Lei de Diretrizes e Bases passa a abordar o mundo do trabalho como parte do processo educativo. Neste sentido, o art. 41 da LDBEN determina que: "O conhecimento adquirido na educação profissional, inclusive no trabalho, poderá ser objeto de avaliação, reconhecimento e certificação para prosseguimento ou conclusão de estudos" (BRASIL, 1996). Respaldando, assim, a criação de políticas públicas voltadas para a certificação profissional de trabalhadores através do reconhecimento dos saberes construídos na experiência de trabalho.

Para regulamentar e normatizar os dispostos a respeito da Educação Profissional na LDB, foram formulados diversos documentos. O primeiro deles, apresentado na gestão do presidente Fernando Henrique Cardoso, foi o Decreto Federal $n^{0}$ 2.208/97, que orienta o cumprimento do $\S 2^{\mathbf{0}}$ do art. 36 e os arts. 39 a 42 da LDB. Este Decreto altera a organização da educação profissional, desvinculando o ensino técnico do ensino de nível médio.

A partir da emissão deste documento, os cursos técnicos passaram a ser divididos em módulos de ensino, e a conclusão de cada um deles dava direito a um certificado de qualificação profissional. Neste sentido, o § $\mathbf{1}^{\mathbf{0}}$ do artigo $8^{\circ}$ define que "[...] no caso do currículo estar organizado em módulos, estes poderão ter caráter de terminalidade para efeito de qualificação profissional, dando direito, neste caso a certificação de qualificação profissional" (BRASIL, 
1997). Os programas de qualificação do trabalhador do qual tratavam o Decreto $n^{\circ} 2.208 / 97$ estavam vinculados à frequência dos módulos dos cursos técnicos, que proporcionariam aos trabalhadores a aquisição de conhecimentos voltados para o exercício de funções demandadas pelo mundo do trabalho, independentemente da escolaridade do sujeito (MORAES; NETO, 2005).

Os conhecimentos construídos ao longo da vida pelos indivíduos poderiam ser certificados para fins de dispensa de disciplinas (ou módulos) em cursos de habilitação do ensino técnico. E, em seu art. 11, "[...] o conjunto de certificados de competência equivalente a todas as disciplinas em módulos que integram uma habilitação profissional dará direito ao diploma correspondente ao técnico de nível médio" (BRASIL, 1997). Assim, cria-se a possibilidade de obtenção de certificação profissional por meio da comprovação de competências ligadas à determinada ocupação.

O Conselho Nacional de Educação (CNE) se manifestou, inicialmente, a respeito do processo de reconhecimento e certificação de saberes por meio da emissão da Resolução CNE/CEB 04/99, que estabelece as Diretrizes Curriculares para a Educação Profissional de Nível Técnico, formulada a partir do disposto no Parecer CNE/CEB 16/99. Em consonância com o disposto no Decreto Federal no 2.208/97, os documentos emitidos pelo CNE interpretam o art. 41 da LDB no sentido de aferimento de conhecimentos para aproveitamento de estudos durante a realização de cursos voltados para educação profissional. Contudo, o CNE estabelece que o certificado de técnico somente será concedido aos egressos dos cursos técnicos que também tivessem concluído o ensino médio, contrariando o disposto no Decreto $\mathrm{n}^{\mathrm{0}} 2.208 / 97$, que estabelecia a certificação como destinada a aqueles que acumulassem os módulos correspondentes a uma especialidade técnica (MORAES; NETO, 2005).

Entendemos que a Resolução CNE/CEB 04/99 apresenta um avanço no que diz respeito à certificação profissional baseada em competências, ao definir, em seu art. 16, que: "O Ministério da Educação, conjuntamente com os demais órgãos federais das áreas pertinentes, ouvido o Conselho Nacional de Educação, organizará um sistema nacional de certificação profissional baseado em competências" (BRASIL, 1999). Expressando a necessidade de se criar um sistema consolidado de certificação profissional respaldada na noção de competências.

No ano de 2004 o Decreto $\mathrm{n}^{0}$ 2.208/97 foi revogado pelo Decreto 5.154/2004, e este passou a definir a forma de organização da Educação Profissional e restabeleceu a integração do ensino técnico ao ensino médio. Esse novo documento define, em seu art. $1^{\circ}$, que a Educação Profissional "[...] será desenvolvida por meio de cursos e programas de formação inicial e continuada de trabalhadores; Educação Profissional Técnica de nível médio; e Educação Profissional Tecnológica, de graduação e de pós-graduação" (BRASIL, 2004a). No entanto, verifica-se que, apesar de tratar 
de diferentes níveis de ensino, o Decreto dá ênfase à educação técnica de nível médio em detrimento das outras formas de educação profissional.

No que diz respeito à formação de trabalhadores, o documento define que os cursos voltados para a capacitação, o aperfeiçoamento e a atualização serão ofertados independentemente do nível de escolaridade, devendo se articular, preferencialmente, aos cursos de educação de jovens e adultos. Contudo, apesar de tratar em seu texto da qualificação de trabalhadores, o novo documento não trata do reconhecimento de saberes construídos fora da instituição escolar para fins de prosseguimento ou conclusão de estudos, tão pouco versa sobre a certificação dos estudantes.

O novo Parecer do CNE que trata sobre o reconhecimento dos saberes adquiridos através do trabalho foi emitido no ano de 2004. O Parecer CNE/CEB no 40/2004 emerge da demanda dos Conselhos Estaduais de Educação pela definição de procedimentos para execução de avaliação, reconhecimento e certificação dos saberes adquiridos no trabalho, uma vez que diversos trabalhadores procuram as instituições de ensino solicitando a legitimação de sua experiência profissional.

Apesar de citar o art. 16 da Resolução CNE/CEB 04/99, este Parecer não trata especificamente sobre a criação do Sistema Nacional de Certificação Profissional e se constitui como uma interpretação normativa dos dispositivos previstos no art. 41 da LDB (BRASIL, 2004b). Por fim, o documento estabelece que cada instituição de ensino deve realizar a avaliação das "competências" profissionais construídas pelos sujeitos no mundo do trabalho, e estabelece ainda que elas precisam ter como "[...] referencial para análise, avaliação e reconhecimento das competências profissionais [...] o perfil profissional de conclusão [de determinado curso], definido pela escola que recebe o aluno, à luz do seu projeto pedagógico" (BRASIL, 2004b, p. 4).

Já no âmbito da regulamentação da educação de jovens e adultos, o Decreto $\mathrm{n}^{0} 5.840 / 2006$, que institui o Programa Nacional de Integração da Educação Profissional com a Educação Básica na modalidade de Educação de Jovens e Adultos (PROEJA), reconhece, em seu art. $7^{\circ}$, a possibilidade de reconhecimento dos "conhecimentos e habilidades obtidos em processos formativos extraescolares" (BRASIL, 2006), e delimita que a aferição destes deve acontecer nas instituições ofertantes de cursos e programas PROEJA. No entanto, o documento não explicita qual a finalidade do reconhecimento destes saberes, de que forma ele está vinculado ao aproveitamento de estudos e a certificação profissional.

Já em 2011, o governo federal criou o Programa Nacional de Acesso ao Ensino Técnico e Emprego (Pronatec), com a função de ofertar cursos de educação profissional de nível médio e cursos de formação inicial e continuada, voltados para a qualificação dos trabalhadores. Juntamente com o Pronatec, criou-se também o programa Bolsa 
Formação Trabalhador, responsável por financiar e ofertar cursos de formação profissional de curta duração (com carga horária mínima de 16oh) para trabalhadores, beneficiários do seguro-desemprego e/ou de programas sociais (BRASIL, 2011). O texto legal que estabelece o Pronatec e o Bolsa Formação não trata especificamente sobre a possibilidade de qualificação profissional por meio do reconhecimento de saberes dos trabalhadores, no entanto, como será explicitado posteriormente, estes programas encontram-se atualmente vinculados à Rede Nacional de Certificação Profissional (Rede Certific).

Frente a esse quadro, pode-se constatar que a legislação educacional brasileira reconhece a importância de outros agentes sociais na construção dos saberes dos sujeitos, estabelecendo que eles podem ser aferidos para fins de prosseguimento ou conclusão dos estudos. Assim sendo, não se pode negar o começo de um movimento que visa a suprir o vazio normativo no que diz respeito ao reconhecimento e certificação de saberes.

Por outro lado, ao contrário do que acontece na legislação educacional, a Consolidação das Leis do Trabalho (CLT) não trata sobre o direito do trabalhador à educação profissional, tampouco sobre a necessidade de reconhecimento e certificação dos saberes destes trabalhadores. Essa lei, entretanto, trata amplamente da normalização do contrato de aprendizagem, por meio do qual a empresa contrata um indivíduo inscrito em programa de aprendizagem técnico-profissional, com o intuito de complementar sua formação, mas não apresenta definições a respeito da qualificação dos trabalhadores já inseridos no mundo do trabalho.

Visando a atender aos dispostos na legislação que versa sobre a educação e a formação de adultos e também às demandas do mercado de trabalho, os Ministérios da Educação e do Trabalho conceberam e implementaram ao longo das últimas duas décadas políticas públicas voltadas para a construção de programas de certificação profissional. Em princípio, estas ações aconteceram separadamente entre os Ministérios, e, no caso do MTE, contou com a participação de outras organizações, conforme será explicitado a seguir.

\section{AS AÇÕES GOVERNAMENTAIS EM BUSCA DE UMA POLÍTICA PÚBLICA DE CERTIFICAÇÃ̃O}

Conforme colocado, a discussão sobre certificação profissional e reconhecimento de saberes foi impulsionada pela promulgação da LDBEN em 1996. Desde então, o MEC e o MTE vêm buscando meios para se discutir e implementar um sistema nacional de certificação profissional.

As formulações de políticas públicas voltadas para a certificação profissional estão enraizadas na distinção conceitual que permeia a organização da educação profissional 
2 Competências entre parêntesis e com ponto de interrogação faz parte do nome do Seminário. existente entre os governos do PSDB, com presidência de Fernando Henrique Cardoso, e do PT, sob a presidência de Luiz Inácio Lula da Silva e Dilma Rousseff. No primeiro, a noção de competências é ordenadora da organização curricular do ensino profissional, assim como das iniciativas de formação e certificação profissional (MORAES; NETO, 2005). Nele, a competência é tida como "[...] capacidade de mobilizar, articular e colocar em ação conhecimentos, habilidades e valores necessários para o desempenho eficiente e eficaz da atividade requerida pela natureza do trabalho" (BRASIL, 1999).

O "modelo de competências" foi incorporado pelo MTE na concepção de programas de formação profissional e no desenvolvimento de ações voltadas para a certificação ocupacional. O primeiro movimento neste sentido foi à realização do Seminário Internacional "Certificação Ocupacional (de competências?) e Equidade" ${ }^{2}$, nos dias 11 e 12 de dezembro de 1997, em Brasília, voltado para apresentação e debate das experiências de certificação internacionais (OIT, 1999).

Este Seminário deu origem ao o projeto "Avanço Conceitual e Metodológico da Formação Profissional no Campo da Diversidade no Trabalho e da Certificação Profissional", realizado pelo MTE em parceria com a OIT e executado entre outubro de 1997 e março de 2002. Durante os quatro anos de Projeto, ocorreram seminários e workshops que estimularam o debate em torno dos aspectos conceituas e metodológicos referentes ao planejamento, gestão e execução de programas de formação e certificação profissional (SOUZA, 2006). Este Projeto, além de ampliar o debate em torno da formação profissional e certificação, subsidiou a construção de diversos documentos que tratam sobre a diversidade do mundo do trabalho e apresentam referenciais metodológicos para a construção de Rede Nacional de Certificação de Competências Profissionais (OIT, 1999).

Paralelamente às ações do MTE, e também calcado no modelo de competências, o MEC elaborou três documentos. O primeiro foi apresentado em fevereiro de 2000, intitulado "Sistema Nacional de Certificação Profissional baseada em Competências - versão preliminar"; o seguinte foi divulgado em outubro do mesmo ano, chamado "Subsistema de Avaliação e Certificação Profissional baseada em Competências"; e o último, de novembro de 2002, "Organização de um Sistema Nacional de Certificação baseada em Competências". De acordo com Morais e Neto (2005, p. 1441), estes documentos, apesar de originário do MEC, tinham como objetivo central "[...] dar cobertura legal às atividades de certificação profissional realizadas fora do âmbito do MEC".

No final de 2002, com base nos documentos emitidos, o MEC apresentou ao Conselho Nacional de Educação uma proposta de construção do Sistema Nacional de Certificação Profissional baseado em Competências - SNCPC, normatizando o art. 16 da Resolução CNE/CEB 04/99. 
3 Ministério do Trabalho e Emprego; Ministério da Educação; Ministério do Turismo; Ministério da Saúde; e Ministério do Desenvolvimento, Indústria e Comércio Exterior.
Após um mês de tramitação, o próprio Ministério cancelou esta proposta esperando que fosse consolidada "[...] uma proposta consensuada socialmente e com a participação dos demais órgãos governamentais que têm como competência a certificação profissional” (IIEP, 2008, p. 2).

Entendemos que a noção de competências que orienta as políticas de certificação profissional durante os anos 1990 está voltada para a formação de trabalhadores com vistas às necessidades do mercado de trabalho. Neste sentido, Ramos (2001 apud SOUZA, 2006, p. 101) afirma que "[...] o conceito de competências traduz a concepção segundo a qual os trabalhadores não possuem conhecimentos necessariamente úteis ao trabalho, mas sim comportamentos úteis à empresa”. Assim, as políticas públicas de qualificação profissional implementadas durante o Governo FHC não se articulavam às ideias de aumento da escolaridade e de inclusão social dos trabalhadores (SOUZA, 2006).

No que diz respeito ao reconhecimento de saberes dos trabalhadores, Morais e Lopes Neto (2005, p. 1439) consideram que:

As políticas de educação desenvolvidas pelo Governo Fernando Henrique Cardoso, tanto as realizadas pelo Ministério da Educação quanto as implementadas pelo Ministério do Trabalho e do Emprego, não propuseram mecanismos para reconhecer conhecimentos dos milhares de jovens e adultos que não concluíram o ensino fundamental e/ou apresentam defasagem idade/escolaridade, e que são portadores de experiências de trabalho, seja para continuidade de estudos, seja para a qualificação e requalificação profissional.

No ano de 2004, com a mudança de governo a qualificação e certificação profissional passaram a ser concebidas como direito social dos trabalhadores, voltados para a inclusão social via aumento de escolaridade. Para Manfredi (2010, p. 4), o sistema de certificação concebido a partir desta visão "[...] pode vir a ser, além de um mecanismo de credenciamento para o trabalho, uma passarela de ingresso/retorno ao sistema escolar formal ou em percursos formativos de natureza continuada".

A alteração das concepções sobre a finalidade da certificação deu origem a ações articuladas da entre vários Ministérios. ${ }^{3}$ Com a finalidade de criar uma política unificada de certificação, o Governo Federal estabeleceu através da Portaria Interministerial $n^{0}$ 24/2004 a Comissão Interministerial de Certificação Profissional. Essa Comissão foi instituída com o objetivo de coordenar as ações governamentais e subsidiar a elaboração e a implantação de políticas públicas de Certificação Profissional (BRASIL, 2005). Nesse contexto, o principal objetivo dessas ações se voltava para a criação de uma Política Nacional de Certificação Profissional. Esta, por sua vez, 
4 Participaram desta experiência como membros do Grupo de Acompanhamento da Experiência piloto: Representantes dos trabalhadores e empresários; CUT; DIEESE; SENAI; representantes do CEFET-SP; Fundação Florestan Fernandes - Diadema; representantes da Secretaria Municipal de Educação do $\mathrm{Mu}-$ nicípio de Diadema; entre outros.
[...] pretende enfrentar o quadro de exclusão social dos trabalhadores agravado pelo baixo índice de escolaridade (a escolaridade média da população brasileira é de seis anos e o índice de analfabetos, em 2001, era de 12,4\%), com uma associação entre o reconhecimento de conhecimentos para fins de qualificação para o trabalho, com o aumento do nível de escolaridade e com a inserção na formação inicial e continuada. (STEFFEN, 2009, p. 62).

No ano de 2005, a referida Comissão criou o Sistema Nacional de Certificação Profissional (SNCP). O intuito era que o SNCP passasse ser o órgão governamental responsável por reunir e regular os dispositivos legais de avaliação, reconhecimento e certificação de saberes construídos fora do ambiente escolar. Além de formular um Repertório Nacional de Qualificações Certificáveis que relacionasse as "[...] qualificações ou arcos ocupacionais passíveis de certificação para fins de reconhecimento de aprendizagem formal e informal ou prosseguimento e conclusão de estudos" (BRASIL, 2005).

Com a intenção de testar o modelo de certificação proposto pelo SNCP, foi implantado, em 2006, o Projeto Piloto de Certificação Profissional nos setores de Construção Civil e Metal-mecânico. A experiência piloto foi estabelecida pelo MTE em parceria com a OIT ${ }^{4}$ e tinha como objetivo elaborar uma estratégia para o desenvolvimento e implementação de instrumentos para qualificação e certificação profissional de trabalhadores, além da certificação de microempresas (ABRAMAT, 2007).

Essa experiência foi finalizada em outubro de 2006, tendo a duração de dez meses, e possibilitou alguns avanços teórico-metodológicos. De acordo com Manfredi (2010), o Projeto Piloto serviu como importante referencial para a formulação de programas de certificação, possibilitando a adoção de uma concepção ampliada da qualificação profissional, que questiona o modelo de certificação de competências, amplamente adotado por outros países.

Apesar de ter sido uma importante experiência, não foram implantados outros Projetos Pilotos no país. Isso porque a minuta do Decreto-Lei enviada pela Comissão Interministerial de Certificação Profissional não foi sancionada, não se criando condições para implementação do SNCP. Diante disso, somente no ano de 2009, o governo brasileiro concretizou a implantação de uma rede nacional de certificação profissional, com a emissão da Portaria Interministerial $\mathrm{n}^{0}$ 1.082/2009, que institui a criação da Rede Nacional de Certificação Profissional - Rede Certific.

\section{A REDE CERTIFIC}

A Rede Certific começou a ser implementada pelo governo federal no ano de 2010 e é definida como uma 
política pública interministerial que conjuga ações dos Ministérios da Educação e do Trabalho e Emprego. Essa Rede tem como objetivo principal desenvolver programas que promovam o reconhecimento e a certificação dos saberes de jovens e adultos desenvolvidos em suas trajetórias de vida e trabalho, para fins de prosseguimento de estudos ou exercício profissional (BRASIL, 2004a).

Os programas ofertados entre os anos 2010 e 2012, os primeiros anos de vigência da Rede Certific, tiveram como público alvo os sujeitos inseridos em postos de trabalho que requerem pouca formação inicial e que são aprendidos no cotidiano das atividades, por exemplo, auxiliar de cozinha, garçom, pedreiro, pintor, entre outros. Contudo, os documentos regulamentadores da Rede abrem possibilidade para certificações profissionais correspondentes a cursos técnicos de nível e médio e também a cursos superiores de tecnologia, inclusive para o reconhecimento de saberes e a certificação de docentes inseridos na educação profissional. Assim sendo, a Portaria MEC no 8/2014 apresenta quatro modalidades distintas de certificação profissional:

a) Certificação de qualificação profissional: correspondente a curso de formação inicial e continuada ou qualificação profissional constante do Catálogo Nacional de Cursos de Qualificação Profissional, ou equivalente, mantido pelo Ministério da Educação MEC; b) Certificação técnica: correspondente a curso técnico de nível médio constante do Catálogo Nacional de Cursos Técnicos, mantido pelo MEC, para possuidores de certificado de conclusão do Ensino Médio; c) Certificação tecnológica: correspondente a curso superior de tecnologia constante do Catálogo Nacional de Cursos Superiores de Tecnologia, mantido pelo MEC, para possuidores de certificado de conclusão do Ensino Médio; d) Certificação docente da educação profissional: correspondente à licenciatura em educação profissional, prevista nas diretrizes curriculares para formação de professores da educação profissional e vinculada ao exercício profissional de professores com mais de 10 (dez) anos de efetivo exercício na educação profissional e tecnológica. (BRASIL, 2014a).

Além do MEC e do MTE, fazem parte da Rede Certific as entidades governamentais e não governamentais com atribuições relacionadas à educação, certificação, metrologia, normalização e regulamentação profissional; as entidades representativas de trabalhadores e empregadores; as instituições da Rede Federal de Educação Profissional, Científica e Tecnológica - Rede Federal; as redes públicas estaduais, distrital e municipais de educação profissional e tecnológica; e as instituições dos Serviços Nacionais de Aprendizagem (SNA). Sendo estas três últimas, as instituições responsáveis pela oferta dos programas da Rede à comunidade, denominadas "unidades certificadoras". 
5 A equipe de avaliação é formada por especialistas da área da certificação almejada e por, no mínimo, um profissional da área técnico-pedagógica (pedagogo, psicólogo ou assistente social).
O processo de reconhecimento de saberes na Rede, por sua vez, é orientado por "perfis de certificação" definidos de acordo os dispostos nos catálogos nacionais de educação profissional e tecnológica, nas diretrizes curriculares para formação de professores da educação profissional ou nos catálogos nacionais de curso de formação inicial e continuada, dependendo do tipo de certificação ofertada. Há aqui uma distinção entre os parâmetros de avaliação adotados na primeira fase de oferta da Rede Certific, que eram elaborados com base em descrições encontradas na Classificação Brasileira de Ocupações (CBO). A justificativa para essa mudança era justamente a inexistência de catálogos que abrangessem todas as esferas de formação descritas anteriormente. Contudo, há um movimento governamental que busca uma aproximação das definições presentes na CBO com aquelas apresentadas nos Catálogos Nacionais elaborados pelo MEC (BRASIL, 2014b), apontando para uma conformação dos programas de educação e formação profissional às necessidades do mercado.

A cada unidade certificadora cabe realizar a elaboração do projeto pedagógico de certificação profissional de cada perfil a ser certificado e também desenvolver metodologias e instrumentos para avaliação dos saberes dos sujeitos. Contudo, estabelecem-se de antemão as etapas do processo de certificação, a saber: inscrição, acolhimento, matrícula, avaliação, certificação e encaminhamento (BRASIL, 2014b).

O ingresso dos trabalhadores nos programas da Rede é regulado por unidades do Sistema Público de Emprego, Trabalho e Renda, particularmente, por unidades do Sistema Nacional de Emprego (SINE). Diferentemente do processo de inscrição adotado na primeira fase da Rede Certific, no qual o trabalhador interessado em participar dos programas da Rede dirigia-se diretamente à instituição de ensino ofertante para realização de seu cadastro, a partir de 2014 a inscrição passou a corresponder à pré-matrícula dos jovens e adultos no programa de Bolsa-Formação Pronatec, efetivando a vinculação entre este e a Rede Certific.

No momento de acolhimento, o sujeito participa de uma entrevista individual com a equipe de avaliação ${ }^{5}$ e preenche um questionário socioprofissional contendo questões sobre sua experiência profissional, escolaridade, organização familiar etc. As informações obtidas nessa primeira etapa estão voltadas para a identificação do perfil do trabalhador e para a definição de estratégias metodológicas para realização do processo de reconhecimento de saberes (BRASIL, 2014b).

A matrícula no processo de certificação é realizada após o processo descrito acima e garante ao trabalhador a condição de aluno regular da instituição ofertante. Uma vez matriculado, o trabalhador passa por avaliações de caráter prático e teórico. De acordo com documento orientador do processo, essas devem ser de caráter descritivo se adequando ao setor profissional a ser certificado, e estar 
voltadas para identificação dos saberes, conhecimentos e competências dos trabalhadores (BRASIL, 2014b). A avaliação se centra no atendimento aos requisitos mínimos estabelecidos nos perfis de certificação como elementos fundamentais para o exercício das atividades.

Ao concluir as avaliações, todos os trabalhadores têm direito a receber um Atestado de Reconhecimento de Saberes Profissionais que registra os conhecimentos, saberes e competências explicitados durante o processo de avaliação, independentemente de terem sido ou não aprovados nos processos avaliativos. Quando o sujeito é capaz de contemplar todos os requisitos do profissional ele fará jus também a um Certificado de Qualificação Profissional correspondente a cursos de FIC e de qualificação profissional que atendem os requisitos do catálogo nacional de cursos de qualificação profissional, ou equivalente, mantido pelo MEC; ou uma Certificação técnica, que se equipara a certificados de cursos técnicos de nível médio descritos no catálogo nacional de cursos técnicos disponibilizado pelo MEC (BRASIL, 2014b). É importante destacar que os documentos regulamentadores da Rede Certific emitidos até o momento não tratam sobre os processos de avaliação que contemplem as certificações tecnológicas e as certificações de docentes da educação profissional, deixando a forma de condução desses dois processos ainda em aberto.

Na primeira fase de oferta de programas da Rede, conduzida majoritariamente pelos IFETs e abrangendo os setores de pesca, construção civil, turismo, música e eletrônica, foram matriculados 3.567 trabalhadores. Destes, 134 trabalhadores obtiveram a certificação profissional almejada; e 1.161 foram encaminhados para cursos de Formação Inicial e Continuada (FIC), visando à requalificação profissional, ou para cursos do PROEJA-FIC, objetivando a conclusão da Educação Básica pelos sujeitos. Contudo, não há informações sobre a trajetória dos 2.272 trabalhadores também inseridos nos Programas (BRASIL, 2014b).

Em seu formato inicial, a proposta da Rede Certific era vincular a certificação dos saberes do trabalhador ao aumento de sua escolaridade, buscando incentivar o (re) ingresso de adultos em instituições de ensino. O intuito era que os trabalhadores com baixo grau de escolaridade, após concluírem o processo de certificação, passassem a frequentar os cursos do Programa Nacional de Integração da Educação Profissional com a Educação Básica na Modalidade de Jovens e Adultos - Formação Inicial e Continuada (PROEJA-FIC) ofertados pelas instituições integrantes da Rede, aqui representadas pelos Institutos Federais de Educação, Ciência e Tecnologia (IFETs).

No entanto, em 2014, a Rede Certific foi passou a se inserir no Pronatec e os programas da Rede foram intitulados Pronatec Certific. Este, por sua vez, foi vinculado ao programa Bolsa Formação Trabalhador, ofertando cursos de qualificação profissional para trabalhadores de diferentes áreas. Nesse novo formato, com a criação da 
modalidade Certificação de qualificação profissional, o Pronatec Certific abre possibilidade para a certificação de trabalhadores independentemente de seu grau de escolaridade, rompendo com um dos principais objetivos colocados anteriormente para a Rede, retomando a ideia de adaptação da qualificação dos trabalhadores às demandas do mercado de trabalho e esvaziando a conteúdo dos programas de formação de trabalhadores conduzidos pelo governo federal.

\section{CONSIDERAÇÕES FINAIS}

Este mergulho nos marcos legais pós LDB e o rastreamento das formulações políticas associados à temática demonstram que o tema é objeto de disputa e controvérsias entre os atores sociais, gestores de políticas públicas e pesquisadores. Gestores ligados ao MTE e ao MEC disputam, no bojo de uma norma de gestão compartilhada interministerial, as orientações teórico-metodológicas e políticas diferenciadas da instituição da Rede Certific no Brasil. Como se não bastasse, um rastreamento do debate no Brasil mostra que muita polêmica cerca as orientações políticas, uma vez que para alguns o que se busca com a implantação deste novo tipo de certificação do trabalho e do reconhecimento dos saberes adquiridos no próprio processo de trabalho é atender às demandas do mercado de trabalho, enquanto para outros estaria havendo uma inflexão nos últimos anos, buscando contemplar demandas históricas dos movimentos sociais pelo reconhecimento de saberes adquiridos na experiência.

Os programas de certificação profissional implementados pelo governo brasileiro até o momento não se estenderam a ponto de gerarem resultados significativos no âmbito da inclusão social. Por outro lado, os dados fornecidos pelo MEC a respeito da quantidade de pessoas que ingressaram e concluíram o processo de certificação na primeira etapa dos programas da Rede Certific nos convidam a repensar profundamente a viabilidade de uma política pública de reconhecimento de saberes e certificação profissional nos moldes concebidos pelo governo federal brasileiro.

As formulações das políticas de certificação profissional representam um avanço no sentido do reconhecimento dos saberes construídos em diferentes locais. Contudo, destaca-se que a formulação de uma política pública que pretenda reconhecer os saberes construídos pelos trabalhadores em sua trajetória profissional deve considerar a complexidade que permeia o mundo do trabalho. No caso da Rede Certific, a vinculação da certificação à exigência de escolaridade desconsidera que a atividade de trabalho comporta saberes que estão formalizados nos currículos escolares e que o trabalho é lócus de formação de conhecimentos de base escolar.

Defendemos que a atividade de trabalho é uma experiência educativa, que forma e transforma o homem. Daí 
provém a importância de políticas públicas voltadas para o reconhecimento de saberes construídos pelos sujeitos durante sua atividade de trabalho. No entanto, o atrelamento dos saberes do trabalho aos saberes escolares nos indica que estas políticas ainda estão voltadas para a legitimação do conhecimento escolar, considerado formal, em detrimento de outras formas de saber. Deve-se, então, ampliar o horizonte teórico sob o qual se analisa o trabalho, já que a formação do homem se dá em vários locais.

No âmbito das opções teórico-metodológicas que orientam o processo de reconhecimento de saberes, a problematização das políticas governamentais de certificação profissional revela um ambiente conflituoso, e este envolve orientações e objetivos diversos, trazendo à tona a dificuldade de se definir estratégias para reconhecimento dos saberes que compõem a atividade de trabalho. A recente vinculação da Rede Certific ao Pronatec revela uma mudança nos tipos de certificação e no processo de ingresso nos programas da Rede, quando tomamos como referência os programas implementados em sua primeira fase, entre 2010 e 2012. No entanto, a forma como a avaliação é concebida, juntamente como a metodologia e seus referenciais permanecem inalterados, parecendo não ser alvo de problematização por parte dos gestores das políticas de formação profissional do governo brasileiro.

Esse problema que perdura deve ser enfrentado do ponto de vista teórico-metodológico e de suas bases epistemológicas. A nosso ver, a metodologia adotada para o reconhecimento de saberes exige outros fundamentos teórico-metológicos para que se possa dar conta de captar os saberes da Educação Básica que são desenvolvidos no curso da atividade de trabalho, estabelecendo-se, assim, uma verdadeira política de reconhecimento de saberes para fins de certificação profissional.

\section{REFERÊNCIAS}

ASSOCIAÇÃO BRASILEIRA DA INDÚSTRIA DE MATERIAIS DE CONSTRUÇÃO. Capacitação e Certificação Profissional na Construção Civil e Mecanismos de Mobilização da Demanda. São Paulo: ABRAT, 2007.

ALCOFORADO, Joaquim Luiz M. Competências, cidadania e profissionalidade: limites e desafios para a construção de um modelo português de educação e formação de adultos. 2008. 460 f. Tese (Doutorado em Ciências da Educação) - Programa de Pós-Graduação em Psicologia e de Ciências da Educação, Universidade de Coimbra, Coimbra, 2008.

BRASIL. Lei $\mathrm{n}^{0}$ 9.394, de 20 de dezembro de 1996. Estabelece as diretrizes e bases da educação nacional. Diário Oficial da República Federativa do Brasil, Brasília, 
DF, 23 dez. 1996. Disponível em: <http://www.planalto.gov.br/ccivil_03/_Ato2011-2014/2014/Lei/L13005. htm>. Acesso em: 13 jan. 2017.

BRASIL. Decreto ${ }^{0}$ 2.208, de 17 de abril de 1997. Regulamenta o $\S 2^{\circ}$ do Art. 36 e os Artigos 39 a 42 da Lei n ${ }^{\circ}$ 9.394. Diário Oficial da República Federativa do Brasil, Brasília, DF, 18 abr. 1997. Disponível em: <http://www. planalto.gov.br/ccivil_03/decreto/d2208.htm>. Acesso em: 10 jan. 2017.

BRASIL. Resolução CNE/CEB no o4/99, de 7 de outubro de 1999. Institui as Diretrizes Curriculares Nacionais para a Educação Profissional de nível técnico. Diário Oficial da República Federativa do Brasil, Brasília, DF, 7 out. 1999. Disponível em: <http://portal.mec.gov.br/setec/arquivos/pdf/resolo499.pdf> . Acesso em: 10 jan. 2017.

BRASIL. Decreto ${ }^{0}$ 5.154, de 23 de julho de 2004. Regulamenta o $\S 2^{\circ}$ do Art. 36 e os Artigos 39 a 42 da Lei 9.394, de 20 de dezembro de 1996, que estabelece as diretrizes e bases da educação nacional, e dá outras providências. Diário Oficial da República Federativa do Brasil, Brasília, DF, 23 jul. 2004. Disponível em: <http://www.planalto. gov.br/ccivil_03/_ato2004-2006/2004/decreto/d5154. htm>. Acesso em: 10 jan. 2017.

BRASIL. Parecer CNE/CEB no 40/2004, de 8 de dezembro de 2004. Trata das normas para execução de avaliação, reconhecimento e certificação de estudos previstos no Artigo 41 da Lei 9.394/96. Diário Oficial da República Federativa do Brasil, Brasília, DF, 8 dez. 2004. Disponível em: Acesso em: 10 jan. 2017.

BRASIL. Sistema Nacional de Certificação Profissional: proposta governamental. Brasília, DF, ago. 2005. Disponível em: http://portal.mec.gov.br/setec/arquivos/ pdf/certifica_minuta.pdf. Acesso em: 23 abr. 2016.

BRASIL. Decreto $\mathrm{n}^{\mathrm{o}} 5.840$, de 13 de julho de 2006. Institui no âmbito federal o Programa Nacional de Integração da Educação Profissional com a Educação Básica na modalidade de Educação de Jovens e Adultos (PROEJA), e dá outras providências. Diário Oficial da República Federativa do Brasil, Brasília, DF, 14 jul. 2006. Disponível em: <http://www.planalto.gov.br/ccivil_03/_ato20042006/2006/decreto/D5840.htm>. Acesso em: 10 jan. 2017.

BRASIL. Lei $\mathrm{n}^{0}$ 12.513, de 26 de outubro de 2011. I n s titui o Programa Nacional de Acesso ao Ensino Técnico e Emprego (Pronatec); altera as Leis no 7.998, de 11 de janeiro de 1990, que regula o Programa do Seguro-Desemprego, o Abono Salarial e institui o Fundo de Amparo ao Trabalhador (FAT), no 8.212, de 24 de julho de 1991, que dispõe sobre a organização da Seguridade Social e institui Plano 
de Custeio, no 10.260, de 12 de julho de 2001, que dispõe sobre o Fundo de Financiamento ao Estudante do Ensino Superior, e no 11.129, de 30 de junho de 2005, que institui o Programa Nacional de Inclusão de Jovens (ProJovem); e dá outras providências. Diário Oficial da República Federativa do Brasil, Brasília, DF, 27 out. 2011. Disponível em: <http://www.planalto.gov.br/ccivil_03/_ato20112014/2011/lei/l12513.htm>. Acesso em: 10 jan. 2017.

BRASIL. Ministério da Educação. Portaria Interministerial MEC/MTE no o4, de 25 de abril de 2014. Dispõe sobre a reorganização da Rede Nacional de Certificação Profissional - Rede Certific. Diário Oficial da República Federativa do Brasil, Brasília, DF, 2 maio 2014a. Disponível em: <http://www.lex.com.br/legis_25477823_PORTARIA_INTERMINISTERIAL_N_5_ DE_25_DE_ABRIL_DE_2014.aspx>. Acesso em: 10 jan. 2017.

BRASIL. Ministério da Educação. Documento referência do Pronatec CERTIFIC. Brasília, DF: MEC, 2014b.

COLARDYN, Danielle.; BJORNAVOLD, Jens. Validation of Formal, Non-Formal and Informal Learning: policy and practices in EU Member States. European Journal of Education, v. 39, n. 1, p. 69 - 89, 2004.

Intercâmbio, Informações, Estudos e Pesquisas. Para entender o Regulamento de Avaliação da Conformidade. São Paulo. 2008. Disponível em: <www.iiep.org.br/ pdfs/doco36.pdf>. Acesso em: 24 nov. 2015.

LIMA, Natália V. Análise do sistema de reconhecimento de saberes e certificação profissional brasileiro: um olhar sobre a Rede CERTIFIC. 2011. Monografia (Graduação em Pedagogia) - Faculdade de Educação, Universidade Federal de Minas Gerais, Belo Horizonte, 2011.

LIMA, Natália V. Reconhecimento de saberes do trabalho e certificação profissional: a experiência da Inglaterra. 2015. 289 f. Dissertação (Mestrado em Educação) - Faculdade de Educação, Universidade Federal de Minas Gerais, Belo Horizonte, 2015.

MANFREDI, Silvia Maria. Uma política de certificação profissional orientada para a inclusão social. Linhas Críticas, Brasília, v. 16, n. 30, p. 1-24, jan./jun. 2010.

MORAES, Carmen Sylvia Vidigal Moraes; NETO, Sebastião Lopes. Educação, formação profissional e certificação de conhecimentos: considerações sobre uma política pública de certificação profissional. Educação e Sociedade, Campinas, v. 26, n. 93, p. 1435-1469, set./dez. 2005. 
ORGANIZAÇÃO INTERNACIONAL DO TRABALHO. Certificação de Competências Profissionais: discussões. Brasília. OIT, MTE/FAT. 1999.

SOUZA, Maria Regina Alves de. Sistema de Certificação Profissional por Competências: um modelo em construção para o Brasil. 2006. 237 f. Dissertação (Mestrado em Sistema de Gestão) - Programa de Pós-Graduação em Sistema de Gestão, Universidade Federal Fluminense, Niterói, 2006.

STEFFEN, Euli Marlene. Sistema de certificação de competências no Brasil e em Portugal. Revista Trabalho e Educação, Belo Horizonte, v. 18, n. 1, p. 61-74, jan./jun. 2009.

STEFFEN, Ivo. A certificação profissional e de pessoas: relato de algumas experiências brasileiras. 1. ed. São Paulo: Editora Érica; SENAI, 2010.

Recebido em: 23/03/2017 Aprovado em: 26/05/2017 